\title{
Genetic Heterogeneity among Patients with Methylcobalamin Deficiency Definition of Two Complementation Groups, cblE and cblG
}

\author{
David Watkins and David S. Rosenblatt \\ Medical Research Council of Canada Genetics Group, Centre for Human Genetics, and Departments of Medicine, \\ Pediatrics, and Biology, McGill University, Montreal, Quebec, Canada H3A 1 Al
}

\begin{abstract}
A number of patients with megaloblastic anemia and homocystinuria associated with low levels of methylcobalamin synthesis in cultured cells have been recognized. Methionine biosynthesis by intact cells, as determined by incorporation of label from 5-[14 C]methyl-tetrahydrofolate into acid-precipitable material, was deficient in cultured skin fibroblasts that were derived from all of these patients. In one group of patients, activity of the methylcobalamin-dependent enzyme, methionine synthase, in cell extracts was within the normal range when the enzyme was assayed under standard conditions. In a second group of patients, methionine synthase activity was decreased under the same assay conditions. Genetic complementation analysis demonstrated the existence of two complementation classes that corresponded to these two groups of patients. The designation cblE has previously been proposed for the mutation in a patient with methylcobalamin deficiency and normal methionine synthase activity. We propose the designation cblG for the mutation in those patients with methylcobalamin deficiency and decreased synthase activity. The results of these studies suggest that the products of at least two loci are required for cobalamin-dependent methionine biosynthesis in mammalian cells.
\end{abstract}

\section{Introduction}

The remethylation of homocysteine to form methionine is catalyzed in mammalian cells by the cytoplasmic enzyme 5methyltetrahydrofolate:homocysteine methyltransferase (EC 2.1.1.13), which is also called methionine synthase $(1,2)$. This enzyme requires methylcobalamin $(\mathrm{MeCbl}){ }^{1}$ a derivative of cobalamin, or vitamin $\mathbf{B}_{12}$, for activity. The metabolism of cobalamin by human cells involves the endocytosis of cobalamin that is bound to the plasma protein transcobalamin II, cleavage of cobalamin from transcobalamin II, translocation of free cobalamin from the lysosome to the cytoplasm, and its conversion to either of two coenzyme derivatives: 5'-deoxy-

Address reprint requests to Dr. David Watkins, Division of Medical Genetics, Department of Medicine, McGill University, 687 Pine Ave., Rm. H5-63, Montreal, Quebec, Canada H3A 1A1.

Received for publication 20 July 1987 and in revised form 21 December 1987.

1. Abbreviations used in this paper: AdoCbl, 5'-deoxyadenosylcobalamin; FBS, fetal bovine serum; MeCbl, methylcobalamin; OHCbl, hydroxycobalamin.

J. Clin. Invest.

(c) The American Society for Clinical Investigation, Inc.

$0021-9738 / 88 / 06 / 1690 / 05 \quad \$ 2.00$

Volume 81, June 1988, 1690-1694 adenosylcobalamin (AdoCbl), which is required for activity of the mitochondrial enzyme methylmalonylCoA mutase; or $\mathrm{MeCbl}$ (3). Our understanding of cobalamin metabolism in mammalian cells has been enhanced by the recognition of a number of inborn errors affecting cobalamin metabolism. These include the cblA and cblB mutations, in which the synthesis of AdoCbl alone is impaired and patients present with cobalamin-responsive methylmalonic aciduria, and the cblC and cblD mutations, in which synthesis of both cobalamin coenzyme derivatives is impaired and patients present with combined methylmalonic aciduria and homocystinuria $(3,4)$. Recently a patient has been described with a mutation, designated cblF, that affects translocation of free cobalamin from the lysosome to the cytoplasm $(5,6)$.

In 1984, a patient was described with an inborn error of cobalamin metabolism that caused decreased synthesis of $\mathrm{MeCbl}$ alone without any effect on AdoCbl synthesis $(7,8)$. The name cblE has been proposed for the mutation in this patient. Subsequently, several patients with a similar disorder have been recognized (9-12). These patients are characterized clinically by developmental retardation, megaloblastic anemia, homocystinuria, and, in most cases, hypomethioninemia, all of which respond to therapy with cobalamin. Studies with cultured fibroblasts from these patients have demonstrated normal cobalamin uptake, decreased synthesis of $\mathrm{MeCbl}$, and decreased intact cell methionine biosynthesis as measured by incorporation of label from $5-\left[{ }^{14} \mathrm{C}\right]$ methyltetrahydrofolate into acid-precipitable material compared with control fibroblasts (8). Synthesis of AdoCbl and activity of the AdoCbl-dependent enzyme methylmalonylCoA mutase were normal. A sibling of the original proband was diagnosed prenatally as having the cblE mutation and his mother was treated with hydroxycobalamin $(\mathrm{OHCbl})$ from the second trimester of pregnancy. Although this individual has been clinically asymptomatic, results of studies with cultured fibroblasts were similar to those with cells from other $\mathrm{MeCbl}$-deficient patients (13).

Although the clinical presentations and the results of studies with cultured fibroblasts were similar for all of these patients, assay of methionine synthase specific activity in extracts of cultured fibroblasts has revealed heterogeneity among them $(10,14)$. In fibroblast extracts from the subject of the original report, enzyme activity was within the normal range when the assay was performed using standard assay conditions, which include $150 \mu \mathrm{M} 2$-mercaptoethanol. Enzyme activity was decreased compared with control values when the assay was repeated using suboptimal concentrations of reducing agent (7, 8). In fibroblast extracts from other patients, methionine synthase activity was decreased even when the assay was performed using optimal conditions $(9,10,14)$. This heterogeneity might be the result of different mutations affecting a single locus, or of mutations affecting two or more separate loci. In the present study, we have investigated the heterogeneity 
among patients with $\mathrm{MeCbl}$ deficiency using complementation analysis. Our results demonstrate that the mutations in these patients affect loci separate from those affected in the $\mathrm{cblC}$ and cblD mutations, and furthermore demonstrate that the mutations in patients with $\mathrm{MeCbl}$ deficiency fall into two complementation classes, perhaps representing mutations at two separate loci.

\section{Methods}

Materials. Cell culture media and fetal bovine serum (FBS) were purchased from Gibco Laboratories, Grand Island, NY; 5- $\left[{ }^{14} \mathrm{C}\right]$ methyltetrahydrofolate from Amersham Corp., Arlington Heights, IL; $S$ adenosylmethionine, DL-homocysteine thiolactone, 5-methyltetrahydrofolate, hydroxycobalamin $(\mathrm{OHCbl})$ and $\mathrm{MeCbl}$ from Sigma Chemical Co., St. Louis, MO; Bio-Rad AG1X8 resin, 200-400 mesh, chloride form, from Bio-Rad Laboratories, Richmond, CA; and polyethylene glycol-1000 (PEG) from the J. T. Baker Chemical Co., Phillipsburg, NJ.

Cell culture. Skin fibroblasts were obtained with informed consent from patients with $\mathrm{MeCbl}$ deficiency. Fibroblasts from patients with the cblC and cblD mutations were provided by Dr. L. E. Rosenberg (Yale University, New Haven, CT) and Dr. S. I. Goodman (University of Colorado, Denver, CO). Strain E1 was provided by Dr. J. C. Haworth, E2 by Dr. S. M. Schmutz (University of Manitoba, Canada), and $\mathrm{E} 3$ by Dr. R. W. Erbe (Harvard University, Cambridge, MA) and Dr. W. J. Rhead (University of Iowa, Iowa City, IA). Strain G1 was provided by Dr. I. T. Thomas (University of Florida, Gainesville, FL) and Dr. R. W. Erbe, G2 by Dr. V. C. McKie and Dr. D. B. Flannery (Medical College of Georgia, Augusta, GA), and G3 by Dr. D. H. Morton and Dr. H. L. Levy (Harvard University). All cell strains were determined to be free of mycoplasma contamination. Cultures were routinely maintained in Eagle's minimum essential medium plus nonessential amino acids (MEM) supplemented with $10 \%$ (vol/vol) FBS. For some experiments, this medium was supplemented with 0.75 $\mu \mathrm{M}$ OHCbl. MEM supplemented with $10 \%$ FBS contains $103 \mu \mathrm{M}$ L-methionine, which is sufficient to support proliferation of both control and MeCbl-deficient fibroblasts. The mutant fibroblasts, unlike control fibroblasts, do not proliferate when methionine in the culture medium is replaced with homocysteine at the same concentration $(7,10)$.

Methionine synthase assay. Fibroblast cultures were trypsinized and resuspended at a density of $1-2 \times 10^{8}$ cells $/ \mathrm{ml}$ in $0.1 \mathrm{M}$ potassium phosphate buffer, $\mathrm{pH}$ 7.4. This cell suspension was sonicated on ice and the sonicate was centrifuged at $4^{\circ} \mathrm{C}$ at $27,000 \mathrm{~g}$ for $60 \mathrm{~min}$. The resulting supernatant (cell extract), which contained 8-26 mg protein/ $\mathrm{ml}$ depending upon the cell strain used, was stored at $-70^{\circ} \mathrm{C}$ until used for enzyme assay.

Enzyme activity was measured by a modification of previously reported techniques $(8,15)$. The assay mixture for measurement of holoenzyme activity contained, in a total volume of $200 \mu \mathrm{l}: 100 \mu \mathrm{l}$ of cell extract; $100 \mathrm{mM}$ potassium phosphate buffer, pH 7.4; $250 \mu \mathrm{M}$ $S$-adenosylmethionine; $500 \mu \mathrm{M}$ DL-homocysteine (prepared fresh daily from the thiolactone); $150 \mathrm{mM}$ 2-mercaptoethanol; and $390 \mu \mathrm{M}$ $5-\left[{ }^{14} \mathrm{C}\right]$ methyltetrahydrofolate $(1.4 \mathrm{dpm} / \mathrm{pmol})$. For measurement of total enzyme (holoenzyme plus apoenzyme) activity, the assay mixture contained in addition $50 \mu \mathrm{M} \mathrm{MeCbl}$.

The assay mixture was incubated with shaking for $60 \mathrm{~min}$ in the dark at $37^{\circ} \mathrm{C}$ in stoppered tubes that had been flushed for $5 \mathrm{~s}$ with nitrogen. The reaction was terminated by addition of $800 \mu \mathrm{l}$ of ice-cold distilled water, and the entire mixture was applied to a syringe column with a bed volume of $1.5 \mathrm{ml}$ Bio-Rad AG1 X8, 200-400 mesh, chloride form resin (Bio-Rad Laboratories). Radioactivity of the entire effluent was measured by liquid scintillation counting.

Cell fusion. After trypsinization, equal numbers of the two cell lines to be tested were mixed and plated into $35-\mathrm{mm}$ tissue culture dishes at a density of $300,000-350,000$ cells per dish. $24 \mathrm{~h}$ after plating, half of the cultures were exposed for $60 \mathrm{~s}$ to a $40 \%$ solution of PEG in PBS to induce cell fusion. The cultures were then washed thoroughly using MEM lacking FBS to remove any residual PEG $(16,17)$. The remaining cultures were not exposed to PEG. Microscopic inspection demonstrated that $\sim 15 \%$ of cells in the PEG-treated cultures contained two or more nuclei. Fused and unfused cultures were incubated for $72 \mathrm{~h}$ in MEM supplemented with $0.75 \mu \mathrm{M} \mathrm{OHCbl}$. At the end of this period, intact cell methionine biosynthesis was measured as described below and compared in parallel fused and unfused cultures to determine whether complementation had taken place.

Intact cell methionine biosynthesis. This was determined from the incorporation of label from $5-\left[{ }^{14} \mathrm{C}\right]$ methyltetrahydrofolate into acidprecipitable material $(18,19)$. Cultures were washed once with PBS and then incubated for $18 \mathrm{~h}$ in MEM supplemented with $50 \mu \mathrm{g} / \mathrm{ml}$ sodium ascorbate, $3.75 \mu \mathrm{M} \mathrm{OHCbl,} \mathrm{and} 10 \%$ dialyzed FBS, in which folic acid had been replaced by $5-\left[{ }^{14} \mathrm{C}\right]$ methyltetrahydrofolate $(0.5$ $\mu \mathrm{Ci} / \mathrm{ml}, 60 \mathrm{mCi} / \mathrm{mmol}$ ), and methionine by DL-homocysteine thiolactone. At the end of this incubation, cellular macromolecules were precipitated with $5 \%$ TCA and radioactivity of the precipitated material was determined by liquid scintillation counting.

\section{Results}

The results of studies using intact cultured fibroblasts demonstrated that the underlying defect was similar in all of the $\mathrm{MeCbl}$-deficient cell strains. Synthesis of $\mathrm{MeCbl}$ from ${ }^{57} \mathrm{Co}-\mathrm{la}-$ beled cyanocobalamin and intact cell methionine biosynthesis, measured by the incorporation of label from $5-\left[{ }^{14} \mathrm{C}\right]-$ methyltetrahydrofolate into acid-precipitable material, were decreased in each of the mutant strains compared with control values. Synthesis of AdoCbl and incorporation of label from $\left[{ }^{14} \mathrm{C}\right]$ propionate into acid-precipitable material, an indirect measure of methylmalonylCoA mutase activity, were normal $(7,8,10-13)$.

Table I shows the results of assay of methionine synthase activity in extracts of control and MeCbl-deficient fibroblasts. Holoenzyme and total enzyme activities were measured in extracts of fibroblasts that had been incubated for $96 \mathrm{~h}$ before

Table I. Methionine Synthase Activity in Extracts of Control and MeCbl-deficient Fibroblasts

\begin{tabular}{|c|c|c|c|c|}
\hline & \multicolumn{4}{|c|}{ Methionine synthase activity } \\
\hline & \multicolumn{2}{|c|}{ Grown without $\mathrm{OHCb}$} & \multicolumn{2}{|c|}{ Grown with $\mathrm{OHCb}{ }^{*}$} \\
\hline & Holoenzyme & Total enzyme & Holoenzyme & Total enzyme \\
\hline & \multicolumn{4}{|c|}{ pmol methionine synthesized/min per $\mathrm{mg}$ protein } \\
\hline Control & $13 \pm 3(12)$ & $48 \pm 8(12)$ & $126 \pm 30(18)$ & $189 \pm 31(16)$ \\
\hline E1 & $19 \pm 4(6)$ & $48 \pm 9(6)$ & $118 \pm 27(9)$ & $134 \pm 40(7)$ \\
\hline E2 & $16 \pm 5(3)$ & $48 \pm 7(3)$ & $92 \pm 10(3)$ & $119 \pm 10(3)$ \\
\hline E3 & $30 \pm 1(3)$ & $49 \pm 3(3)$ & $86 \pm 3(3)$ & $90 \pm 5(3)$ \\
\hline G1 & $4 \pm 2(5)$ & $10 \pm 4(6)$ & $13 \pm 5(11)$ & $21 \pm 9(12)$ \\
\hline G2 & $3 \pm 2(6)$ & $12 \pm 9(6)$ & $4 \pm 2(9)$ & $12 \pm 6(9)$ \\
\hline G3 & $2 \pm 1(6)$ & $8 \pm 6(4)$ & $30 \pm 8(7)$ & $56 \pm 12(9)$ \\
\hline
\end{tabular}

Values represent means \pm SD of the indicated number of determinations.

* Cells were incubated for $96 \mathrm{~h}$ before harvest in medium supplemented with $0.75 \mu \mathrm{M}$ OHCbl. Cell extracts were prepared and methionine synthase activity was determined in these extracts as described in Methods.

Holoenzyme, enzyme to which $\mathrm{MeCbl}$ is bound; total enzyme, holoenzyme plus apoenzyme. 
harvest in either MEM or MEM supplemented with $0.75 \mu \mathrm{M}$ $\mathrm{OHCbl}$. OHCbl at this concentration has been shown to stimulate activity of methionine synthase. All assays were performed using standard assay conditions, including $150 \mathrm{mM}$ 2-mercaptoethanol. Holoenzyme and total enzyme activities in extracts of three of the mutant cell strains (designated E1, $\mathrm{E} 2$; and E3 in the table) were similar to those of control extracts under the same assay conditions. On the other hand, activity in extracts of three other cell strains (G1, G2, and G3) was decreased to a variable extent relative to activity of control extracts. The MeCbl-deficient cell lines thus could be divided into two groups on the basis of methionine synthase activity measured under optimal reducing conditions.

The results of complementation analysis of two MeCbl-deficient cell strains, one (E1) with normal synthase activity and one (G1) with decreased synthase activity under standard assay conditions, with one another and with cblC $(\mathrm{Cl}$ and $\mathrm{C2})$ and cblD (D1) cell strains, are shown in Table II. Intact cell methionine biosynthesis was compared in parallel fused and unfused cultures. Exposure of unmixed cultures of any of the mutant cell strains forr $60 \mathrm{~s}$ to a $40 \%$ solution of PEG resulted in a very small increase or an actual decrease in methionine biosynthesis. Intact cell methionine biosynthesis was increased, compared with that of parallel unfused cultures, in fused mixed cultures of cell strain E1 with either cblC or cblD cells, indicating that complementation had occurred, as expected, between these cell strains. Similarly, complementation occurred between cell strain Gl and cblC and cblD cells.

Table II. Complementation of MeCbl-deficient Cells with cblC and cblD Cells

\begin{tabular}{lccc}
\hline & \multicolumn{3}{c}{ Methionine biosynthesis } \\
\cline { 2 - 4 } & Unfused & Fused & Difference \\
\hline \multicolumn{4}{c}{ pmol methyltetrahydrofolate incorporated/mg protein } \\
per $18 h$ & \\
Control & $361 \pm 14$ & $341 \pm 17$ & $-20 \pm 9$ \\
E1 & $57 \pm 1$ & $54 \pm 4$ & $-3 \pm 3$ \\
G1 & $12 \pm 1$ & $13 \pm 1$ & $+1 \pm 0.3$ \\
C1 & $83 \pm 15$ & $89 \pm 7$ & $+6 \pm 22$ \\
C2 & $54 \pm 4$ & $47 \pm 2$ & $-7 \pm 5$ \\
D1 & $119 \pm 9$ & $122 \pm 3$ & $+3 \pm 11$ \\
E1 $\times$ C1 & $92 \pm 18$ & $180 \pm 8$ & $+88 \pm 26$ \\
E1 $\times$ C2 & $53 \pm 1$ & $107 \pm 4$ & $+54 \pm 5$ \\
E1 $\times$ D1 & $77 \pm 6$ & $205 \pm 27$ & $+128 \pm 23$ \\
G1 $\times$ C1 & $65 \pm 3$ & $107 \pm 17$ & $+42 \pm 18$ \\
G1 $1 \times$ C2 & $48 \pm 1$ & $90 \pm 4$ & $+42 \pm 6$ \\
G1 $\times$ D1 & $79 \pm 1$ & $130 \pm 5$ & $+51 \pm 5$ \\
E1 $\times$ G1 & $43 \pm 1$ & $142 \pm 7$ & $+99 \pm 7$ \\
& & & \\
\hline
\end{tabular}

Intact cell methionine biosynthesis as measured by the incorporation of label from $5-\left[{ }^{14} \mathrm{C}\right]$ methyltetrahydrofolate into acid-precipitable material as described in Methods was determined in cultures of fibroblasts from patients with $\mathrm{MeCbl}$ deficiency and normal methionine synthase activity in cell extracts (E1), MeCbl deficiency and decreased methionine synthase activity in cell extracts (G1), cblC disease $(\mathrm{Cl}, \mathrm{C} 2)$, and cblD disease (D1). Values were determined in unmixed and mixed cultures, with (fused) and without (unfused) exposure to PEG. Values are means \pm SD of triplicate determinations. A positive value for the difference in intact cell methionine biosynthesis between fused and unfused cultures indicates that complementation has occurred.
Table III. Complementation Analysis of Fibroblasts from $\mathrm{MeCbl}$-deficient Patients

\begin{tabular}{|c|c|c|c|c|c|}
\hline \multicolumn{6}{|c|}{ Methionine biosynthesis } \\
\hline & E1 & E3 & G1 & G2 & G3 \\
\hline & \multicolumn{5}{|c|}{ pmol methyltetrahydrofolate incorporated/mg protein per $18 \mathrm{~h}$} \\
\hline \multirow[t]{5}{*}{ E1 } & $-1 \pm 0.6$ & $-1 \pm 2$ & $+44 \pm 11$ & $+40 \pm 6$ & $+26 \pm 14$ \\
\hline & E3 & $+1 \pm 4$ & $+34 \pm 18$ & $+42 \pm 18$ & $+26 \pm 3$ \\
\hline & & G1 & $+2 \pm 2$ & $+2 \pm 2$ & $0 \pm 5$ \\
\hline & & & G2 & $-1 \pm 0.5$ & $+2 \pm 3$ \\
\hline & & & & G3 & $-5 \pm 8$ \\
\hline
\end{tabular}

Values shown are the mean differences $( \pm \mathrm{SD})$ in intact cell methionine biosynthesis between parallel fused and unfused cultures; a positive value indicates that complementation has taken place. Values are the means of two experiments, each including triplicate determinations.

Complementation also occurred between cell strains E1 and G1. The magnitude of the stimulation of intact cell methionine biosynthesis was similar in fused, mixed cultures of cell strains E1 and G1 and in fused, mixed cultures of either of these cell strains and cblC or cblD cells.

Table III summarizes the results of complementation analysis of five MeCbl-deficient cell strains. Each of these cell strains has been shown to complement with cblC and cblD cells. In no case did exposure of a mutant cell strain to $40 \%$ PEG result in a large increase in intact cell methionine biosynthesis. Each of the cell strains tested fell into one of two complementation classes. Those cell strains with normal methionine synthase activities in cell extracts under standard assay conditions, cell strains E1 and E3, constituted one of the complementation classes; those cell strains with diminished methionine synthase activity in cell extracts under these conditions, cell strains G1, G2, and G3, made up the second complementation class. In addition, cell strain E2, derived from the affected sibling of patient $\mathrm{E} 1$, was shown in additional experiments to fall within the first complementation class.

\section{Discussion}

Each of the patients studied in this report presented in infancy with developmental retardation, megaloblastic anemia, and homocystinuria, all of which responded to therapy with cobalamin. Studies using intact cultured fibroblasts from these patients also yielded mostly similar results $(8,10-13)$. In all cases, synthesis of $\mathrm{MeCbl}$ from labeled precursor and intact cell methionine biosynthesis were deficient. In five out of the six cell strains, synthesis of AdoCbl and intact cell propionate fixation, a measure of the functional integrity of methylmalonylCoA mutase, were normal; in the sixth strain, G3, intact cell propionate fixation was decreased in the presence of normal AdoCbl synthesis (11). The basis for this finding is at present unclear.

Assay of methionine synthase activity in extracts of $\mathrm{MeCbl-deficient} \mathrm{cell} \mathrm{lines,} \mathrm{however,} \mathrm{disclosed} \mathrm{heterogeneity}$ among these patients. In one group of cell strains (designated E1, E2, and E3 in Table I), synthase activity fell within the normal range when the assay was performed under standard assay conditions, which include relatively high concentrations of reducing agent. It has previously been shown in two of these 
cell strains (E1 and E2) that synthase activity was decreased relative to that of control extracts when the assay was performed using suboptimal concentrations of reducing agent $(8$, 13). Similar results were obtained with cell strain E3 (unpublished data). In the second group of cell strains, G1, G2, and G3, methionine synthase activity was decreased relative to that of control extracts even under optimal assay conditions. The effect of altering reducing conditions on methionine synthase activity in extracts of these cells is difficult to interpret because of the low level of enzyme activity that is present even under optimal assay conditions.

The question of whether this heterogeneity arises as the result of mutations affecting more than one locus was addressed by complementation analysis. The results of this analysis demonstrated the existence of two complementation classes among these patients (Table III). One of these classes consisted of those patients with normal methionine synthase in cell extracts activity under standard assay conditions. This class includes the subject of the original reports of a patient with what was designated the cblE mutation $(7,8)$. We propose the designation cblG for the second class, in which methionine synthase activity in cell extracts was decreased relative to that of control extracts even under optimal assay conditions. The patients included in this new complementation class have been previously reported as cblE $(10,11)$ or cblE-variant $(12)$ patients.

We have now studied cultured fibroblasts from 11 patients with $\mathrm{MeCbl}$ deficiency. In all cases, methionine synthase activity is low in extracts of cblG fibroblasts, but not in those of cblE fibroblasts, when the assay is carried out using standard assay conditions. Intact cell methionine biosynthesis, measured under the conditions of the present study which involve preincubation of cultures in medium supplemented with $\mathrm{OHCbl}$ for $3 \mathrm{~d}$ before assay, tended to be lower in cblG than in cblE cell strains. This difference was not seen in all strains, however, and G3 had values as high or higher than any of the cblE strains, whereas two of the five cblE strains had values within the range of the other cblG strains. These results suggest further heterogeneity among both the cblE and cblG subgroups. At the present time, differentiation between the cblE and $\mathrm{cblG}$ groups among patients with $\mathrm{MeCbl}$ deficiency thus depends upon either assay of methionine synthase specific activity in fibroblast extracts or complementation analysis.

The existence of two complementation clàsses among patients with $\mathrm{MeCbl}$ deficiency suggests that the products of at least two separate loci may be required for cobalamin-dependent methionine synthesis in mammalian cells. Interallelic complementation has been observed in mutations that affect enzymes composed of multiple identical subunits $(16,20,21)$. Since we do not now know the identity of the gene product or products affected by the cblE and cblG mutations, the possibility of interallelic complementation in the present study cannot be formally ruled out. The magnitude of the increase in methionine biosynthesis observed in fusions between cblE and cblG cells, however, is similar to that observed between cells from either of these two complementation classes and cblC and cblD cell strains (Table II), which are expected to affect a separate locus or loci. These results are more consistent with intergenic than with interallelic complementation, because the magnitude of complementation is generally less in cases of interallelic complementation than that observed in cases of intergenic complementation (21). The only enzyme currently known to play a role in cobalamin-dependent methionine bio- synthesis, methionine synthase, apparently consists of three nonidentical subunits (22). Interallelic complementation would not be expected to occur if the cblE and cblG mutations affected a gene encoding one subunit of this enzyme.

The identity of the loci affected by the cblE and cblG mutations are not yet known. Cobalamin-dependent methionine biosynthesis has been studied in some detail using methionine synthase purified from Escherichia coli $(1,2)$. In this system, synthesis of $\mathrm{MeCbl}$ occurs as a part of the catalytic cycle of methionine synthase. A deficiency of $\mathrm{MeCbl}$ thus could arise as a consequence of impaired functioning of methionine synthase. An NADP-dependent reducing system that consists of two flavoproteins required to maintain the enzyme in its active form also has been described $(23,24)$. Purification of methionine synthase from mammalian sources has proved difficult, and similar detailed studies using the mammalian enzyme have not yet been reported. It has been previously suggested that the cblE mutation affects a reducing system analogous to that in $E$. coli (8), whereas the cblG mutation could arise as the result of a mutation affecting the methionine synthase enzyme itself. While the bacterial reducing system apparently does not function with the mammalian enzyme, mammalian methionine synthase may contain thiol oxidase activity that plays a similar role as an integral part of the protein (25). In any case, the cblE and cblG mutations should provide a powerful tool for investigating the mechanisms of methionine biosynthesis in man.

\section{Acknowledgments}

We thảnk Nora Matiaszuk, Angela Hosack, Dr. Bernàtd A. Cooper, and Helena Lue-Shing for their assistance.

Dr. Watkins is a Postdoctoral Fellow and Dr. Rosenblatt is a Principal Investigator in the Medical Research Council of Canada Genetics Group. This is a publication of the Hess B. and Diane Finestone Laboratory in memory of Jacob and Jenny Finestone.

\section{References}

1. Taylor, R. T. 1983. $\mathrm{B}_{12}$-dependent methionine biosynthesis. In $B_{12}$. D. Dolphin, editor. John Wiley \& Sons, Inc., New York. 307-355.

2. Matthews, R. G. 1984. Methionine biosynthesis. In Folates and Pterins. Vol. 1. R. L. Blakley and S. J. Bencovic, editors. John Wiley \& Sons Inc., New York. 497-553.

3. Rosenberg, L. E. 1983. Disorders of propionate and methylmalonate metabolism. In The Metabolic Basis of Inherited Disease, 5th ed. J. B. Stanbury, J. B. Wyngaarden, D. S. Frederickson, J. L. Goldstein, and M. S. Brown, editors. McGraw-Hill Book Co., New York. 474-497.

4. Cooper, B. A., and D. S. Rosenblatt. 1987. Inherited defects of vitamin $\mathrm{B}_{12}$ metabolism. Annu. Rev. Nutr. 7:291-320.

5. Rosenblatt, D. S., A. Hosack, N. V. Matiaszuk, B. A. Cooper, and $R$. Laframboise. 1985. Defect in vitamin $\mathbf{B}_{12}$ release from lysosomes: newly described inborn error of vitamin $B_{12}$ metabolism. Science (Wash. DC). 228:1319-1321.

6. Rosenblatt, D. S., R. Laframboise, J. Pichette, P. Langevin, B. A. Cooper, and T. Costa. 1986. New disorder of vitamin $B_{12}$ metabolism (cobalamin F) presenting as methylmalonic aciduria. Pediatrics. 78:51-54.

7. Schuh, S., D. S. Rosenblatt, B. A. Cooper, M. L. Schroeder, A. J. Bishop, L. E. Seargeant, and J. C. Haworth. 1984. Homocystinuria and megaloblastic anemia responsive to vitamin $B_{12}$ therapy. An inborn error of metabolism due to a defect in cobalamin metabolism. $N$. Engl. J. Med. 310:686-690.

8. Rosenblatt, D. S., B. A. Cooper, A. Pottier, H. Lue-Shing, N. Matiaszuk, and K. Grauer. 1984. Altered vitamin $B_{12}$ metabolism in 
fibroblasts from a patient with megaloblastic anemia and homocystinuria due to a new defect in methionine biosynthesis. J. Clin. Invest. 74:2149-2156.

9. Hallam, L. J., M. Sawyer, A. C. L. Clark, and M. B. Van Der Weyden. 1987. Vitamin $B_{12}$ responsive neonatal megaloblastic anemia and homocystinuria with associated reduced methionine synthase activity. Blood. 69:1128-1133.

10. Rosenblatt, D. S., I. T. Thomas, D. Watkins, B. A. Cooper, and R. W. Erbe. 1987. Vitamin $B_{12}$-responsive homocystinuria and megaloblastic anemia: heterogeneity in methylcobalamin deficiency (cblE). Am. J. Med. Genet. 26:377-383.

11. Morton, D. H., H. L. Levy, M. I. Bresnan, C. A. Hall, D. Watkins, and D. S. Rosenblatt. 1986. Cobalamin (cbl) E mutation with developmental delay, myoclonic seizures and hypsarrythmia. Therapy with methylcobalamin. Am. J. Hum. Genet. 39:A16. (Abstr.)

12. McKie, V. C., R. A. Roesal, F. A. Hommes, D. Watkins, D. S. Rosenblatt, and D. B. Flannery. 1986. Clinical findings in an infant with methylcobalamin deficiency (cblE variant). Am. J. Hum. Genet. 39:A71. (Abstr.)

13. Rosenblatt, D. S., B. A. Cooper, S. M. Schmutz, W. A. Zaleski, and R. E. Casey. 1985. Prenatal vitamin $B_{12}$ therapy of a fetus with methylcobalamin deficiency (cobalamin E disease). Lancet. i:11271129.

14. Watkins, D., and D. S. Rosenblatt. 1986. Heterogeneity in functional methionine synthase deficiency. In Chemistry and Biology of Pteridines 1986. Pteridines and Folic Acid Derivatives. B. A. Cooper and V. M. Whitehead, editors. Walter de Gruyter, Berlin. 713-716.

15. Taylor, R. T., and H. Weissbach. 1973. $\mathrm{N}^{5}$-methyltetrahydrofolate-homocysteine methyltransferases. In The Enzymes. Vol. 9B. D. Boyer, editor. Academic Press, Inc., London/New York. 121-163.

16. McInnes, R. R., V. Shih, and S. Chilton. 1984. Interallelic complementation in an inborn error of metabolism: genetic heteroge- neity in arginosuccinate lyase deficiency. Proc. Natl. Acad. Sci. USA. 81:4480-4484.

17. Watkins, D., and D. S. Rosenblatt. 1986. Failure of lysosomal release of vitamin $B_{12}$ : a new complementation group causing methylmalonic aciduria (cblF). Am. J. Hum. Genet. 39:404-408.

18. Hoffman, R. M., and R. W. Erbe. 1976. High in vivo rates of methionine biosynthesis in transformed human and malignant rat cells auxotrophic for methionine. Proc. Natl. Acad. Sci. USA. 75:1523-1527.

19. Willard, H. F., I. S. Mellman, and L. E. Rosenberg. 1978. Genetic complementation among inherited deficiencies in methylmalonylCoA mutase activity: evidence for a new class of human cobalamin mutant. Am. J. Hum. Genet. 30:1-13.

20. Nadler, H. L., C. M. Chacko, and M. Rachmeler. 1975. Interallelic complementation in hybrid cells derived from human diploid strains deficient in galactose-1-phosphate uridyl transferase activity. Proc. Natl. Acad. Sci. USA. 67:976-982.

21. Gravel, R. A., K. F. Lam, K. J. Scully, and Y. E. Hsia. 1977. Genetic complementation of propionyl-CoA carboxylase deficiency in cultured human fibroblasts. Am. J. Hum. Genet. 29:378-388.

22. Utley, C. S., P. D. Marcell, R. H. Allen, A. C. Antony, and J. F. Kolhouse. 1985. Isolation and characterization of methionine synthase from human placenta. J. Biol. Chem. 260:13656-13665.

23. Fujii, K., and F. M. Huennekens. 1974. Activation of methionine synthetase by a reduced triphosphopyridine nucleotide-dependent flavoprotein system. J. Biol. Chem. 249:6745-6753.

24. Fujii, K., J. H. Galivan, and F. M. Huennekens. 1977. Activation of methionine synthase: further characterization of the flavoprotein system. Arch. Biochem. Biophys. 178:662-670.

25. Matthews, R. G., D. A. Jencks, V. Frasca, and K. D. Matthews. 1986. Methionine biosynthesis. In Chemistry and Biology of Pteridines 1986. Pteridines and Folic Acid Derivatives. B. A. Cooper and V. M. Whitehead, editors. Walter de Gruyter, Berlin. 697-707. 